\title{
Diretrizes e indicadores de acompanhamento das políticas de proteção à saúde da pessoa idosa no Brasil
}

\author{
Guidelines and monitoring indicators of the elderly protection policies in \\ Brazil
}

\section{Directrices e indicadores de monitoreo de las políticas de protección al anciano en Brasil}

Dalia Elena Romero ${ }^{1, a}$

dalia.romero@icict.fiocruz.br | https://orcid.org/oooo-0002-2643-9797

Debora Castanheira Pires ${ }^{1,2, b}$

deboracastanheira1@gmail.com | https://orcid.org/0000-0001-6995-1259

Aline Marques ${ }^{1,0}$

alinepmarques.fiocruz@gmail.com | https://orcid.org/oooo-0002-9072-5333.

Jessica Muzy ${ }^{1, d}$

jessica.rodrigues@icict.fiocruz.br | https://orcid.org/0000-0003-2526-2317

${ }^{1}$ Fundação Oswaldo Cruz, Instituto de Comunicação e Informação Científica e Tecnológica em Saúde. Rio de Janeiro, RJ, Brasil.

${ }^{2}$ Universidade do Estado do Rio de Janeiro, Instituto de Estudos Sociais e Políticos. Rio de Janeiro, RJ, Brasil.

a Doutorado em Saúde Pública pela Fundação Oswaldo Cruz.

${ }^{\text {b }}$ Doutorado em Ciência Política pela Universidade do Estado do Rio de Janeiro.

' Doutorado em Epidemiologia e Saúde Pública pela Fundação Oswaldo Cruz.

d Mestrado em Informação e Comunicação em Saúde pelo Fundação Oswaldo Cruz.

\section{Resumo}

O Brasil se destaca na América Latina pela alta institucionalização de políticas de proteção à pessoa idosa. Contudo, um problema para sua consolidação é a falta de indicadores para seu acompanhamento. O objetivo deste artigo é propor indicadores sensíveis às dimensões da saúde contempladas nas políticas em vigor voltadas para esta população. O estudo foi dividido em três etapas. Na primeira, foi traçado um panorama das políticas voltadas para a pessoa idosa e foram identificadas as diretrizes e metas comuns no que tange à saúde. Na segunda, foram selecionados indicadores sociais e de saúde para acompanhamento das áreas temáticas. Na terceira, foram calculados indicadores para o Brasil e suas grandes regiões. Considerando esta análise preliminar, podemos concluir que, apesar de ser possível calcular indicadores para o acompanhamento de políticas a partir das fontes de dados disponíveis, limitações concernentes à oportunidade dos dados, sua desagregabilidade e confiabilidade restringem sua utilização para o aprimoramento das políticas nacionais.

Palavras-chave: Políticas públicas; Saúde do idoso; Indicadores; Avaliação em saúde; Saúde pública. 


\begin{abstract}
The high level of institutionalization of Brazilian social policies for the elderly stands out in Latin America. However, a problem underlying its consolidation is the lack of indicators for their monitoring and evaluation. This paper aims to propose indicators that are sensitive to the different dimensions of health policies carried out for this population. The study is divided in three stages of research. On the first it was outlined an overview of the main public health policies dedicated to the elderly and identified common guidelines and goals concerning health. On the second stage we selected social and health indicators to follow the thematic areas. The third stage consisted in calculating the indicators proposed for Brazil and its macroregions. Considering the preliminary analysis, we can conclude that although it is possible to calculate sensitive indicators to follow the health policies using data sources available in Brazil, limitations regarding the timeliness of the data, their disaggregability and reliability restrict their use in the improvement of public policies.
\end{abstract}

Keywords: Public policies; Health of the elderly; Indicators; Health evaluation; Public health.

\title{
Resumen
}

Brasil se destaca en América Latina por la alta institucionalización de políticas de protección a los ancianos. Sin embargo, un problema para su consolidación es la falta de indicadores para su seguimiento y apreciación suya. El objetivo de este artículo es proponer indicadores sensibles a las dimensiones de salud de las políticas dirigidas a esta población. El estudio se dividió en tres etapas. en la primera, ha sido trazado un panorama de las políticas dirigidas hacia los ancianos y fueron identificadas las directrices y metas comunes en salud. En la segunda, han sido seleccionados indicadores sociales y de salud para seguimiento de las áreas temáticas. En la tercera, se calcularon indicadores para Brasil y sus grandes regiones. En este análisis preliminar, podemos concluir que, no obstante sea posible calcular indicadores a partir de las fuentes de datos disponibles, limitaciones concernientes a la oportunidad de los datos, su desagregación y confiabilidad suya restringen su utilización para el perfeccionamiento de las políticas públicas.

Palabras clave: Políticas públicas; Salud del anciano; Indicadores; Evaluación de la salud; Salud pública.

Contribuição dos autores:

Concepção e desenho do estudo: Dalia Romero; Débora Castanheira.

Aquisição, análise ou interpretação dos dados: Débora Castanheira, Jéssica Muzy, Aline Marques.

Redação do manuscrito: Débora Castanheira, Aline Marques.

Revisão crítica do conteúdo intelectual: Dalia Romero.

Declaração de conflito de interesses: não há.

Fontes de financiamento: não houve.

Considerações éticas: não há.

Agradecimentos/Contribuições adicionais: não há.

Histórico do artigo: submetido: 20 ago. 2018 | aceito: 13 dez. 2019 | publicado: 29 mar. 2019.

Apresentação anterior: não há.

Licença CC BY-NC atribuição não comercial. Com essa licença é permitido acessar, baixar (download), copiar, imprimir, compartilhar, reutilizar e distribuir os artigos, desde que para uso não comercial e com a citação da fonte, conferindo os devidos créditos de autoria e menção à Reciis. Nesses casos, nenhuma permissão é necessária por parte dos autores ou dos editores. 


\section{Introdução}

No Brasil, as quedas nos níveis de mortalidade a partir de 1940 e de natalidade por volta de 1960 resultaram em mudanças na estrutura etária da população, levando o país de predominantemente jovem a ser considerado em processo de envelhecimento ${ }^{1}$. Em 2017, pessoas com 60 anos ou mais representavam $12,51 \%$ da população brasileira e estimativas do IBGE apontam que esse valor deve chegar a $29 \%$ em 2050. Ao mesmo tempo, a situação epidemiológica brasileira é marcada pelo aumento de prevalência de doenças crônicas não transmissíveis (DCNT), características das faixas etárias mais elevadas² ${ }^{2}$ em concomitância com uma agenda não concluída de infecções e desnutrição, além do crescimento de causas externas ${ }^{3}$.

Em razão dessas mudanças, a saúde da população idosa se tornou um dos problemas mais importantes para a investigação e o planejamento de políticas públicas. Na verdade, a pressão orçamentária sobre o sistema de saúde relacionada ao aumento da população idosa com DCNT, às limitações provocadas por elas e à perda de anos de vida saudáveis é considerada por muitos pesquisadores como um dos principais fatores para o equilíbrio fiscal do Estado brasileiro nos anos vindouros ${ }^{4-6}$.

Alinhado com a posição internacional sobre o tema, o Brasil tem formulado diversas políticas públicas voltadas para a população idosa a fim de garantir direitos sociais e de cidadania para este grupo etário. Desde o final dos anos 1980, o país elaborou um vasto conjunto de leis, decretos, portarias e políticas que tomaram os idosos como público-alvo incluindo desde normas exigíveis imediatamente (como direito ao transporte público gratuito) até normas-diretrizes para a ação do Estado (como a instrução para diminuir as desigualdades sociais nesse grupo etário e colocar a funcionalidade no centro da definição de saúde dos idosos, por exemplo). Por isso, de acordo com estudos desenvolvidos pela Cepal sobre a institucionalidade social na América Latina ${ }^{7,8}$, o Brasil e o México são os países que se destacam com maior grau de institucionalização das políticas sociais, seguidos por Argentina, Costa Rica, Peru e Uruguai. O Brasil é considerado um dos países que efetiva os acordos internacionais em matéria de envelhecimento.

Assim, a partir da transformação no conceito de saúde alavancada pela Constituição Federal de 1988 $(\mathrm{CF} / 88)^{9}$, o país aprovou, por exemplo, a Política Nacional do Idoso (PNI) ${ }^{10}$, a Política Nacional de Saúde da Pessoa Idosa (PNSPI) ${ }^{11}$ e o Estatuto do Idoso ${ }^{12}$, além de ter se tornado signatário de diversos acordos internacionais na área, como o Plano de Ação Internacional para o Envelhecimento, de $2002^{13}$. A saúde da pessoa idosa também fez parte de importantes instrumentos de organização do Sistema Único de Saúde (SUS), como o Pacto pela Saúde (2006) $)^{14}$ e o Contrato Organizativo de Ação Pública - Coap (2011) ${ }^{15}$.

No caso da saúde, a criação do SUS rompeu com a lógica securitária de organização da atenção e inaugurou um paradigma baseado no combate aos determinantes sociais de saúde. A assistência social experimentou avanços com a promulgação da Lei Orgânica de Assistência Social - Loas (Lei 8.742/93) ${ }^{16}$, que sedimentou seu caráter de direito não contributivo e buscou superar o caráter filantrópico que sempre marcou a área. Mesmo na Previdência Social, que mantém a lógica contributiva, verificou-se o afrouxamento do vínculo contributivo como princípio estruturante do sistema, legitimando programas de transferência de renda do porte da aposentadoria rural ${ }^{17,18}$.

Partindo dessas profundas mudanças institucionais, a área de proteção à pessoa idosa no Brasil foi reestruturada. A incorporação da questão do envelhecimento nas políticas públicas não é nova. A influência e pressões da sociedade civil, de associações científicas (como a Sociedade Brasileira de Geriatria e Gerontologia) e de grupos políticos fizeram com que, a partir da década de 1970, o governo federal adotasse iniciativas na prestação de proteção ao idoso, principalmente na área de assistência social. Na verdade, a preocupação pública com as necessidades acarretadas pelo processo de envelhecimento foi alavancada, em grande parte, pela organização social dos idosos, realçando o protagonismo do movimento social ${ }^{19}$.

Apesar de o Brasil ser considerado pioneiro na criação de leis e políticas públicas que visam à proteção social da pessoa idosa, um problema subjacente à consolidação dessas medidas é a falta de indicadores 
sensíveis para seu acompanhamento ${ }^{20}$. Mesmo quando há produção regular de dados, não há equivalente regularidade de análise orientada para as necessidades da gestão.

É importante notar que existem diversas iniciativas que buscam responder a essa questão, dentre elas podemos destacar a Rede Interagencial de Informações para a Saúde (Ripsa), fundada em 1995 por uma parceria entre o Ministério da Saúde (MS) e a Organização Panamericana de Saúde (Opas/OMS). A Ripsa tem como propósito justamente promover "a disponibilidade adequada e oportuna de dados básicos, indicadores e análises sobre as condições de saúde e suas tendências, visando aperfeiçoar a capacidade de formulação, gestão e avaliação de políticas e ações públicas pertinentes”21. Contudo, não obstante os grandes avanços, as políticas de saúde da pessoa idosa permanecem uma área que recebe pouca atenção.

Considerando essa lacuna, o objetivo deste trabalho é propor indicadores sensíveis às diversas dimensões da saúde contempladas nas metas e medidas das políticas em vigor voltadas para a população idosa no Brasil. Com isso, pretendemos contribuir tanto para o debate sobre avaliação de políticas públicas no Brasil, quanto fornecer instrumentos adequados para acompanhar as transformações na qualidade de vida e na saúde da população idosa.

\section{Metodologia}

O presente trabalho foi dividido em três etapas de pesquisa. Na primeira, identificaram-se diretrizes, objetivos e metas comuns, no que tange à saúde, entre as principais políticas públicas voltadas para a pessoa idosa aprovadas no país após a CF/88 ${ }^{9}$. A revisão partiu da Política Nacional do Idoso (PNI) ${ }^{10}$, Política Nacional de Saúde da Pessoa Idosa (PNSPI) ${ }^{11}$, do Estatuto do Idoso ${ }^{12}$ e do Plano de Ação Internacional para o Envelhecimento ${ }^{13}$. Apenas as políticas em vigor na data da revisão, que ocorreu nos meses de outubro e novembro de 2017, foram incluídas na busca. Foram excluídas políticas já revogadas e que contemplavam outros grupos populacionais.

Na segunda etapa de pesquisa foram selecionados indicadores sociais e de saúde, diretos e indiretos, para acompanhamento das políticas públicas identificadas na primeira etapa. Foram identificadas também as fontes de dados nacionais de acesso livre existentes para cálculo desses indicadores. As seguintes fontes foram incluídas para análise: os Sistemas de Informações em Saúde (SIS) do Ministério da Saúde, os censos demográficos de 2000 e 2010, o Suplemento Saúde da Pesquisa Nacional por Amostra de Domicílio (Pnad) de 2008, a Pesquisa Nacional de Saúde (PNS) de 2013 e os dados administrativos do Ministério de Desenvolvimento Social (MDS). A seleção dos indicadores de acompanhamento teve como critério a disponibilidade de fonte de dados de abrangência nacional. Indicadores que, embora relevantes, não tivessem bases de dados adequadas para cálculo não foram considerados neste trabalho.

Uma vez que indicadores cumprem muitas funções no ciclo de políticas públicas (fornecem dados para o planejamento das intervenções, para monitorar a implementação de programas e avaliar seus resultados), é improvável que um indicador seja suficiente para cumprir todas essas funções. Jannuzzi ${ }^{22}$ sugere que o acompanhamento de programas sociais seja realizado por meio de quatro tipos de indicadores: insumo (correspondem às medidas associadas à disponibilidade de recursos humanos, financeiros ou de equipamentos), processo (traduzem o esforço operacional de alocação de recursos), resultado (são aqueles vinculados aos objetivos finais dos programas públicos, que permitem avaliar a eficácia do cumprimento das metas especificadas) e impacto (referem-se aos efeitos e desdobramentos mais gerais, antecipados ou não, que decorrem da implantação do programa).

Os indicadores utilizados na segunda etapa deste artigo são vinculados aos objetivos finais dos programas e voltados para avaliar a eficácia do cumprimento de metas. Esses indicadores são importantes porque permitem um juízo ágil, baseado em critérios técnicos sobre o estado geral de uma determinada área temática. Esta apreciação é muitas vezes insuficiente para fazer um julgamento acurado sobre o 
estado de um programa ou política, mas tem a vantagem de subsidiar a construção de hipóteses para um acompanhamento mais integral e mais preciso.

A terceira e última etapa consistiu no cálculo e análise dos indicadores propostos. Os indicadores foram calculados para grandes regiões do país e para o Brasil. A série histórica de cada indicador analisado abrangeu os últimos anos disponíveis de cada fonte de dados.

\section{Resultados}

\section{Panorama das políticas em vigor voltadas para a população idosa no Brasil}

A Constituição Federal de $1988^{9}$ redefiniu os moldes da proteção social no Brasil, ao incorporar a concepção de seguridade como expressão dos direitos inerentes à cidadania. O novo modelo reestruturou as áreas de previdência (elaborada como seguro social), assistência (entendida como direito e não como filantropia) e saúde (pública e universal) sob a égide da universalidade, o que exigiu um redimensionamento institucional significativo dessas políticas.

A Política Nacional do Idoso (PNI), instituída pela Lei $8.842 / 1994^{10}$ e regulamentada pelo Decreto $1.948 / 1996^{23}$, foi um documento pioneiro no Brasil e colocou a questão do envelhecimento e da velhice numa ótica transversal que diz respeito a vários ministérios, à família e à sociedade ${ }^{14}$. Seu principal avanço foi inaugurar um novo paradigma de políticas para a pessoa idosa, estabelecendo princípios a partir dos quais as ações deveriam ser desenvolvidas. De acordo com o art. $3^{\circ}$ da PNI, são princípios norteadores das ações voltadas para a população idosa: "I) a responsabilidade compartilhada entre família, Estado e sociedade na garantia dos direitos do idoso; II) informação a toda a sociedade sobre o processo de envelhecimento; III) não discriminação; IV) protagonismo da pessoa idosa; e V) observação das diferenças econômicas, sociais, regionais e, particularmente, as contradições entre o meio rural e o urbano"”.

A PNI foi fruto de um intenso processo de participação social ${ }^{24}$. Contudo, sua implementação foi prejudicada pelo contexto de austeridade fiscal dos anos 1990, principalmente em razão da baixa prioridade dada à atenção ao idoso no contexto de implementação do SUS e das políticas de assistência social, o que se refletiu na pouca institucionalização desta política. Tanto no âmbito da saúde quanto da assistência social foram criados poucos incentivos administrativos e financeiros para sua implementação.

A preocupação com os direitos do idoso continua a crescer no campo internacional e sendo absorvida pelo Brasil. Em 1999, o país incorpora através do Decreto 3.321 o Protocolo de São Salvador ${ }^{25}$ (protocolo adicional à Convenção Americana de Direitos Humanos), que trata especificamente da pessoa idosa em seu art. 17, e busca garantir ao idoso o gozo dos direitos básicos à alimentação, atenção médica e trabalho. Isso torna este instrumento obrigatório para o Brasil. 


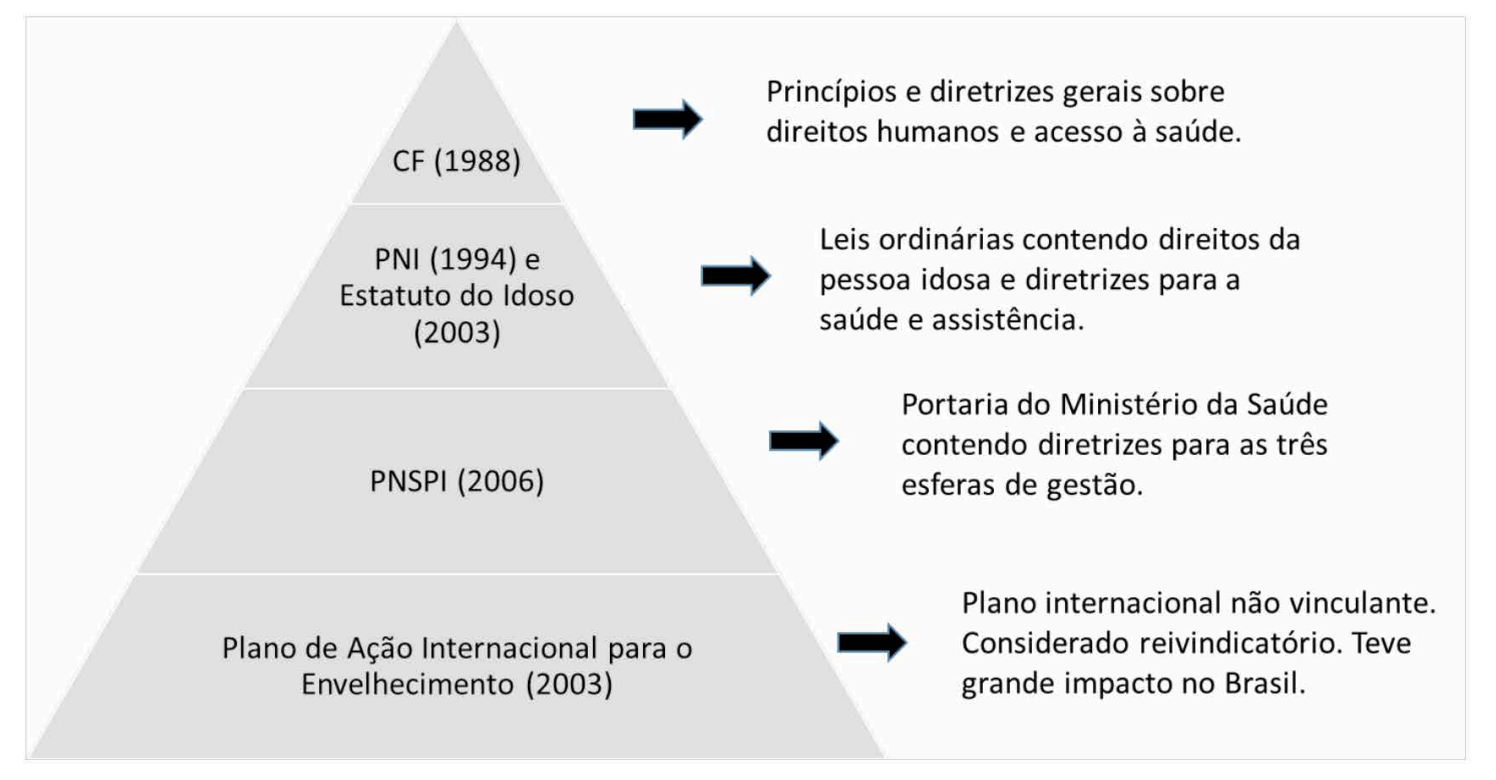

Figura 1 - Panorama dos instrumentos de proteção à pessoa idosa no ordenamento jurídico brasileiro Fonte: Os autores (2019).

No entanto, apesar de não ser uma norma que gera direitos e deveres exigíveis no ordenamento jurídico brasileiro, o instrumento internacional que mais afeta a maneira como o Brasil entende os direitos da pessoa idosa é Plano de Ação Internacional para o Envelhecimento, concebido em Madrid no ano de $2002^{13}$. Este Plano possui 35 objetivos e 239 recomendações para os governos nacionais e tem como objetivo garantir que, em todas as partes do mundo, a população possa envelhecer com segurança e dignidade, e que os idosos possam continuar participando em suas respectivas sociedades como cidadãos com plenos direitos. Esse documento busca oferecer um instrumento prático para ajudar os responsáveis pela formulação de políticas a considerar as prioridades básicas associadas com o envelhecimento dos indivíduos e das populações. As recomendações para a adoção de medidas organizam-se em três direções prioritárias: os idosos e o desenvolvimento; promover a saúde e o bem-estar até a chegada da velhice; e criar ambientes propícios e favoráveis aos idosos. Além disso, ganha destaque especial a atenção aos países em desenvolvimento, nos quais o processo de envelhecimento populacional vem se dando de maneira mais intensa e acelerada. O Plano de Ação Internacional para o Envelhecimento, da Organização das Nações Unidas $^{13}$ (ONU), teve suas orientações declaradamente incorporadas pela Política Nacional de Saúde da Pessoa Idosa (PNSPI) ${ }^{11}$ do Ministério da Saúde.

Talvez o aspecto mais importante do Plano seja a incorporação do conceito de capacidade funcional. De acordo com a Classificação Internacional de Funcionalidade - $\mathrm{CIF}^{26}$, a funcionalidade é um termo que engloba todas as funções do corpo, atividades e participação; de maneira similar, incapacidade é um termo que inclui deficiências, limitação da atividade ou restrição na participação. Esse conceito surgiu como um novo paradigma de saúde ${ }^{27}$, particularmente importante quando consideramos o envelhecimento populacional. De fato, um indivíduo idoso portador de doenças crônicas pode ser considerado saudável, se comparado com um idoso com as mesmas doenças, porém sem controle destas, com sequelas e incapacidades associadas ${ }^{28}$.

Em 1999, foi estabelecida a Política Nacional de Saúde do Idoso (Portaria MS/GM no 1.395/99 ${ }^{29}$ ), na qual se determinou que os órgãos do Ministério da Saúde relacionados ao tema promovessem a elaboração ou a adequação de planos, projetos e ações em conformidade com as diretrizes e responsabilidades estabelecidas na lei. Esta política reconhecia a perda da capacidade funcional e mental como uma das principais consequências do envelhecimento. Em 2006, a Política Nacional de Saúde do Idoso passou a ser conhecida como Política Nacional de Saúde da Pessoa Idosa, conforme veremos adiante. 
Em 2002, foi proposta a organização e implantação de Redes Estaduais de Assistência à Saúde do Idoso (Portaria GM/MS n ${ }^{0} 702 / 2002^{30}$ ), tendo como base a condição de gestão e a divisão de responsabilidades, definidas pela Norma Operacional de Assistência à Saúde (NOAS 2002 ${ }^{31}$ ). Como parte de operacionalização das redes, são criados os critérios para cadastramento dos Centros de Referência em Atenção à Saúde do Idoso.

Contudo, o principal marco legal no que se refere à população idosa é a Lei 10.741, de $1^{\circ}$ de outubro de $2003^{12}$, que dispõe sobre o Estatuto do Idoso, instrumento destinado a regular os direitos assegurados às pessoas com idade igual ou superior a 60 (sessenta) anos. A partir desse momento, o Estatuto passa a ser um documento central de referência para que as políticas públicas sejam adequadas ao processo de envelhecimento populacional ${ }^{32}$. A saúde aparece como um elemento de destaque no Estatuto, possuindo um capítulo próprio que dispõe sobre os direitos dos idosos na área. Uma vez que o envelhecimento está constantemente associado a um declínio biológico representado por doenças, perda de autonomia e dependência, o acesso aos serviços de saúde, além da educação e renda, modifica fortemente a qualidade de vida dessa população.

Em 2006, foi aprovada a Política Nacional de Saúde da Pessoa Idosa (Portaria MS/GM 2.528/06) ${ }^{11}$, atualizando a antiga Política Nacional do Idoso. Esta Portaria traz um novo paradigma para a discussão da situação de saúde dos idosos e incorpora a concepção de envelhecimento ativo, conforme recomendação da Organização das Nações Unidas. Na perspectiva desta política, o envelhecimento bem-sucedido pode ser entendido a partir de três componentes: a) menor probabilidade de doença; b) alta capacidade funcional física e mental; e c) engajamento social ativo. $\mathrm{O}$ alcance desses fatores requer uma visão do envelhecimento como um processo que deve ser trabalhado a partir das idades mais jovens e, por isso mesmo, requer ações preventivas e de promoção de condições de saúde e de vida.

O Quadro 1 consolida em áreas temáticas os objetivos e diretrizes comuns da PNI, do Plano de Ação Internacional para o Envelhecimento, do Estatuto do Idoso e da PNSPI no que tange à saúde da pessoa idosa. Nele são identificadas as sete principais áreas temáticas comuns das políticas voltadas para essa questão. As preocupações centrais dos instrumentos são o acesso aos serviços de saúde e a prevenção e manutenção da funcionalidade. No que se refere ao acesso, o Plano, como é de se esperar de um instrumento internacional, apresenta apenas indicações gerais sobre a necessidade de desenvolvimento de serviços adequados às necessidades da população idosa. Da mesma forma, a $\mathrm{PNI}^{10}$ se restringe a garantir o direito à assistência médica. Documentos mais recentes, como o Estatuto do $\operatorname{Idoso}^{12}$ e a PNSPI ${ }^{11}$ já apresentam diretrizes mais robustas, que podem ser resumidas - em concordância com a Política Nacional de Atenção Básica - na ênfase na atenção primária resolutiva, no cadastramento da população em base territorial e na criação de uma linha de cuidado. 
Quadro 1 - Políticas de saúde da pessoa idosa por área temática

(continua)

\begin{tabular}{|c|c|c|c|c|}
\hline Área temática & $\begin{array}{l}\text { PNI (Lei } \\
8.842 / 94)\end{array}$ & $\begin{array}{l}\text { Plano (UN } 2^{\circ} \text { World } \\
\text { Assembly on Ageing, } \\
\text { Madrid, 2002) }\end{array}$ & $\begin{array}{l}\text { Estatuto (Lei } \\
10.741 / 03 \text { ) }\end{array}$ & $\begin{array}{l}\text { PNSPI (Portaria MS/GM } \\
2.528 / 06 \text { ) }\end{array}$ \\
\hline \multirow[t]{2}{*}{$\begin{array}{l}\text { Acesso aos } \\
\text { serviços de } \\
\text { saúde }\end{array}$} & $\begin{array}{l}\text { Garantir ao idoso } \\
\text { a assistência } \\
\text { à saúde, nos } \\
\text { diversos níveis } \\
\text { de atendimento } \\
\text { do SUS (art. 10, } \\
\text { II, a) }\end{array}$ & $\begin{array}{l}\text { Desenvolvimento e } \\
\text { fortalecimento dos } \\
\text { serviços de assistência } \\
\text { à saúde para atender } \\
\text { às necessidades de } \\
\text { idosos (Orient prior II, } \\
\text { Tema 2, Obj 2) }\end{array}$ & $\begin{array}{l}\text { Cadastramento } \\
\text { da população } \\
\text { idosa em base } \\
\text { territorial (art. } \\
\left.15, \S 1^{\circ}, \mathrm{I}\right)\end{array}$ & $\begin{array}{l}\text { Desenvolver e valorizar o } \\
\text { atendimento acolhedor e } \\
\text { resolutivo à pessoa idosa, } \\
\text { baseado em critérios de risco } \\
\text { (Diretriz } 3.1, \text { «») }\end{array}$ \\
\hline & $\begin{array}{l}\text { Criar serviços } \\
\text { alternativos de } \\
\text { saúde (art. 10, } \\
\text { II, h) }\end{array}$ & $\begin{array}{l}\text { Instituir um } \\
\text { atendimento contínuo à } \\
\text { saúde para atender às } \\
\text { necessidades de idosos } \\
\text { (Orient prior II, Tema } \\
\text { 2, Obj 3) }\end{array}$ & $\begin{array}{l}\text { Atendimento } \\
\text { geriátrico e } \\
\text { gerontológico } \\
\text { em ambulatórios } \\
\left.\text { (art. } 15, \S 1^{\circ}, \mathrm{II}\right)\end{array}$ & $\begin{array}{l}\text { Atenção integral e integrada, } \\
\text { estruturada nos moldes } \\
\text { de uma linha de cuidado } \\
\text { (Diretriz } 3.1, \S 1^{\circ} \text { ) }\end{array}$ \\
\hline \multirow[t]{2}{*}{$\begin{array}{l}\text { Prevenção e } \\
\text { manutenção } \\
\text { da capacidade } \\
\text { funcionaL }\end{array}$} & $\begin{array}{l}\text { Prevenir, } \\
\text { promover, } \\
\text { proteger e } \\
\text { recuperar a } \\
\text { saúde do idoso, } \\
\text { mediante } \\
\text { programas } \\
\text { e medidas } \\
\text { profiláticas (art. } \\
10, \text { II, b) }\end{array}$ & $\begin{array}{l}\text { Redução dos efeitos } \\
\text { acumulativos } \\
\text { dos fatores que } \\
\text { aumentam o risco } \\
\text { de sofrer doenças e, } \\
\text { em consequência, a } \\
\text { possível dependência } \\
\text { na velhice. (Orient } \\
\text { prior II, Tema 1, Obj 1) }\end{array}$ & $\begin{array}{l}\text { Reabilitação } \\
\text { orientada pela } \\
\text { geriatria e } \\
\text { gerontologia, } \\
\text { para redução } \\
\text { das sequelas } \\
\text { decorrentes do } \\
\text { agravo da saúde } \\
\text { (art. } 15, \S 1^{\circ}, \mathrm{V} \text { ) }\end{array}$ & $\begin{array}{l}\text { Incluir ações de reabilitação } \\
\text { para a pessoa idosa na } \\
\text { atenção primária de modo } \\
\text { a intervir no processo que } \\
\text { origina a dependência } \\
\text { funcional (Diretriz } 3.1, \text { «») }\end{array}$ \\
\hline & & $\begin{array}{l}\text { Manutenção de } \\
\text { máxima capacidade } \\
\text { funcional durante toda } \\
\text { a vida e promoção da } \\
\text { plena participação dos } \\
\text { idosos portadores de } \\
\text { incapacidades (Orient } \\
\text { prior II, Tema 6, Obj 1) }\end{array}$ & & \\
\hline \multirow[t]{2}{*}{$\begin{array}{l}\text { Violência e } \\
\text { maus-tratos }\end{array}$} & & $\begin{array}{l}\text { Eliminação de todas as } \\
\text { formas de abandono, } \\
\text { abuso e violência } \\
\text { contra idosos (Orient } \\
\text { prior II, Tema 3, Obj 1) }\end{array}$ & \multirow{2}{*}{$\begin{array}{l}\text { Nenhum idoso } \\
\text { será objeto de } \\
\text { qualquer tipo } \\
\text { de negligência, } \\
\text { discriminação, } \\
\text { violência, } \\
\text { crueldade ou } \\
\text { opressão (art. } \\
4^{\circ} \text { ), sendo a } \\
\text { notificação pelos } \\
\text { serviços de saúde } \\
\text { compulsória (art. } \\
\text { 19) }\end{array}$} & $\begin{array}{l}\text { Realizar ações integradas } \\
\text { de combate à violência } \\
\text { doméstica e institucional } \\
\text { (Diretriz } 3.1, \ll f » \text { ) }\end{array}$ \\
\hline & & $\begin{array}{l}\text { Criação de serviços } \\
\text { de apoio para atender } \\
\text { aos casos de abuso e } \\
\text { maus-tratos a idosos } \\
\text { (Orient prior II,Tema 3, } \\
\text { Obj 2) }\end{array}$ & & \\
\hline
\end{tabular}


(conclusão)

\begin{tabular}{|c|c|c|c|c|}
\hline Área temática & $\begin{array}{l}\text { PNI (Lei } \\
8.842 / 94)\end{array}$ & $\begin{array}{l}\text { Plano (UN } 2^{\circ} \text { World } \\
\text { Assembly on Ageing, } \\
\text { Madrid, 2002) }\end{array}$ & $\begin{array}{l}\text { Estatuto (Lei } \\
10.741 / 03 \text { ) }\end{array}$ & $\begin{array}{l}\text { PNSPI (Portaria MS/GM } \\
2.528 / 06 \text { ) }\end{array}$ \\
\hline $\begin{array}{l}\text { Moradia } \\
\text { adequada }\end{array}$ & $\begin{array}{l}\text { Incluir nos } \\
\text { programas de } \\
\text { assistência ao } \\
\text { idoso formas } \\
\text { de melhoria de } \\
\text { condições de } \\
\text { habitabilidade } \\
\text { e adaptação } \\
\text { de moradia, } \\
\text { considerando } \\
\text { seu estado } \\
\text { físico e sua } \\
\text { independência de } \\
\text { locomoção (art. } \\
\left.10, V_{,} \ll b »\right)\end{array}$ & $\begin{array}{l}\text { Melhoria do projeto } \\
\text { ambiental e da moradia } \\
\text { para promover a } \\
\text { independência de } \\
\text { idosos considerando } \\
\text { suas necessidades, } \\
\text { particularmente dos } \\
\text { que apresentam } \\
\text { incapacidades (Orient } \\
\text { prior III, Tema 1, Obj } \\
\text { 2) }\end{array}$ & $\begin{array}{l}\text { O idoso tem } \\
\text { direito à moradia } \\
\text { digna, no seio da } \\
\text { família natural } \\
\text { ou substituta, ou } \\
\text { desacompanhado } \\
\text { de seus } \\
\text { familiares, } \\
\text { quando assim } \\
\text { o desejar, ou, } \\
\text { ainda, em } \\
\text { instituição } \\
\text { pública ou } \\
\text { privada. (art. 37) }\end{array}$ & \\
\hline \multirow[t]{2}{*}{$\begin{array}{l}\text { Participação na } \\
\text { comunidade }\end{array}$} & $\begin{array}{l}\text { Incentivar e criar } \\
\text { programas de } \\
\text { lazer, esporte } \\
\text { e atividades } \\
\text { físicas que } \\
\text { proporcionem } \\
\text { a melhoria da } \\
\text { qualidade de } \\
\text { vida do idoso e } \\
\text { estimulem sua } \\
\text { participação na } \\
\text { comunidade (art. } \\
10, \text { VII, «e») }\end{array}$ & $\begin{array}{l}\text { Reconhecimento da } \\
\text { contribuição social, } \\
\text { cultural, econômica e } \\
\text { política das pessoas } \\
\text { idosas. (Orient prior I, } \\
\text { Tema 1, Obj 1) }\end{array}$ & $\begin{array}{l}\text { Viabilização } \\
\text { de formas } \\
\text { alternativas de } \\
\text { participação, } \\
\text { ocupação e } \\
\text { convívio do idoso } \\
\text { com as demais } \\
\text { gerações (art. } 3^{\circ}, \\
\S 1^{\circ}, \text { IV) }\end{array}$ & $\begin{array}{l}\text { Facilitar a participação } \\
\text { das pessoas idosas em } \\
\text { equipamentos sociais, } \\
\text { grupos de terceira idade, } \\
\text { atividade física, conselhos } \\
\text { de saúde locais e conselhos } \\
\text { comunitários onde o } \\
\text { idoso possa ser ouvido e } \\
\text { apresentar suas demandas } \\
\text { e prioridades (Diretriz 3.1., } \\
\text { «g») }\end{array}$ \\
\hline & $\begin{array}{l}\text { Viabilização } \\
\text { de formas } \\
\text { alternativas de } \\
\text { participação, } \\
\text { ocupação e } \\
\text { convívio do } \\
\text { idoso, que } \\
\text { proporcionem } \\
\text { sua integração às } \\
\text { demais gerações. } \\
\text { (art. } 4^{\circ}, \mathrm{I} \text { ) }\end{array}$ & & & $\begin{array}{l}\text { Promover a participação } \\
\text { nos grupos operativos e } \\
\text { nos grupos de convivência, } \\
\text { com ações de promoção, } \\
\text { valorização de experiências } \\
\text { positivas e difusão dessas } \\
\text { na rede, nortear e captar } \\
\text { experiências (Diretriz 3.1., } \\
\text { «i») }\end{array}$ \\
\hline \multirow[t]{2}{*}{$\begin{array}{l}\text { Assistência } \\
\text { social }\end{array}$} & & $\begin{array}{l}\text { Redução da pobreza } \\
\text { entre as pessoas idosas }\end{array}$ & \multirow{2}{*}{$\begin{array}{l}\text { Aos idosos que } \\
\text { não possuam } \\
\text { meios para } \\
\text { prover sua } \\
\text { subsistência, } \\
\text { nem de tê-la } \\
\text { provida por } \\
\text { sua família, é } \\
\text { assegurado o } \\
\text { benefício mensal } \\
\text { de } 1 \text { salário- } \\
\text { mínimo, nos } \\
\text { termos da LOAS } \\
\text { (art. 34). }\end{array}$} & \multirow[t]{2}{*}{$\begin{array}{l}\text { É dever da assistência } \\
\text { social desenvolver ações de } \\
\text { enfrentamento à pobreza } \\
\text { (Item } 5.3, \ll \mid »)\end{array}$} \\
\hline & & $\begin{array}{l}\text { Renda mínima } \\
\text { suficiente para idosos, } \\
\text { com especial atenção } \\
\text { aos grupos em situação } \\
\text { social e econômica } \\
\text { desvantajosa. }\end{array}$ & & \\
\hline
\end{tabular}

Fonte: Os autores, adaptado de PNI (Lei 8.842/1994), Plano de Ação Internacional para o Envelhecimento, Estatuto do Idoso (Lei 10.741/03) e PNSPI (Portaria MS/GM 2.528/06). 
No caso das medidas preventivas e de manutenção da saúde, como já mencionado acima, o Plano (internacional) introduz o paradigma da funcionalidade, que foi posteriormente incorporada na PNSPI. O arcabouço político brasileiro, em conformidade com o pensamento internacional, considera que no cenário do envelhecimento populacional - aumento exponencial da população idosa e consequentemente da carga de doenças crônicas não transmissíveis (DCNT) potencialmente incapacitantes - a expectativa de vida passa a ser analisada levando em conta não apenas a sobrevida, mas também os anos vividos livres de incapacidade ${ }^{27}$. O conceito contemporâneo de saúde considera saudável o indivíduo com plena capacidade funcional, mesmo que seja diagnosticado com múltiplas DCNT. Esse conceito privilegia a independência e a autonomia do indivíduo no dia a dia como variáveis fundamentais.

O combate à violência e aos maus-tratos também é uma área temática importante, cuja medida mais relevante está no Estatuto do Idoso: a notificação compulsória dos casos de violência pelos serviços de saúde. A partir desse momento, emergem questões sobre a disponibilidade, as condições de funcionamento dos serviços de denúncia e proteção aos idosos, além da necessidade de criação de serviços específicos para esse grupo populacional.

Os hábitos individuais que contribuem para a exposição diferencial a fatores de risco à saúde como, por exemplo, o tabagismo e o sedentarismo - ou seja, o estilo de vida - também são parte importante das políticas brasileiras voltadas para a população idosa. Eles aparecem primeiro no Plano Internacional para o Envelhecimento e são subsequentemente incorporadas na PNSPI. Estes fatores despontam nas políticas principalmente por serem considerados Determinantes Sociais de Saúde, uma vez que ultrapassam o limiar das responsabilidades individuais em razão da forte influência que sofrem de informações, propagandas, pressão dos pares, possibilidade de acesso a alimentos saudáveis e espaços de lazer, entre outros ${ }^{33}$. Modificar tais fatores no curso da vida contribuiria para a redução da prevalência de DCNT na população idosa, representando ganhos consideráveis de vida saudável.

A moradia adequada é essencial para garantir a saúde e o bem-estar da pessoa idosa e, por isso, é garantida por diversos instrumentos na PNI, no Plano de Ação Internacional para o Envelhecimento e no Estatuto do Idoso. Indicadores relacionados às condições de moradia podem ajudar a entender o nível de exclusão social ao qual a população idosa de um determinado espaço geográfico está submetida.

A participação da pessoa idosa na comunidade, termo que caracteriza a convivência social, aparece em todas as políticas identificadas. Ela é um dos componentes essenciais de um envelhecimento ativo e saudável. A solidão e a falta de apoio social além de serem um problema conhecido na velhice também são fatores de risco importantes para a depressão nessa faixa ${ }^{34}$. Outro tema relevante é a assistência social, voltada principalmente para a garantia de uma renda mínima na idade avançada.

\section{Proposição de indicadores por áreas temáticas}

Este segmento tem como objetivo propor indicadores de acompanhamento das políticas de saúde voltadas para a população no Brasil, considerando as áreas temáticas comuns definidas na seção anterior. O interesse por indicadores e sua aplicação na formulação e avaliação de ações governamentais vem crescendo no país. Tal fato deve-se tanto às mudanças institucionais da administração pública que vem consolidando o planejamento como parte da rotina de tomada de decisões, quanto ao aprimoramento dos controles administrativos, com ênfase em auditoria e avaliação ${ }^{22}$. Não obstante, as políticas de saúde em geral, e as voltadas para as pessoas idosas em particular, têm como problema subjacente a falta de indicadores sensíveis.

Os indicadores sugeridos no Quadro 2 podem ser classificados como de resultado, ou seja, são aqueles vinculados aos objetivos finais dos programas públicos, que permitem avaliar a eficácia do cumprimento das metas especificadas. Com esses indicadores é possível realizar um juízo ágil e baseado em critérios técnicos sobre o estado geral de uma determinada área temática, apesar de não serem suficientes para fazer um julgamento acurado sobre o estado de um programa ou política. 


\begin{tabular}{|c|c|c|c|c|c|}
\hline Área temática & Indicador & Definição & Fonte & $\begin{array}{l}\text { Abrangência } \\
\text { geográfica }\end{array}$ & $\begin{array}{l}\text { Período } \\
\text { disponível }\end{array}$ \\
\hline $\begin{array}{l}\text { Acesso aos } \\
\text { serviços de } \\
\text { saúde }\end{array}$ & $\begin{array}{l}\text { Proporção de idosos } \\
\text { cadastrados na } \\
\text { Estratégia Saúde da } \\
\text { Família (ESF) }\end{array}$ & $\begin{array}{l}\text { Proporção de domicílios com moradores idosos de } 60 \text { anos, ou } \\
\text { mais, cadastrados numa Unidade de Saúde da Família. }\end{array}$ & $\begin{array}{l}\text { 2008: PNAD (Pesquisa } \\
\text { Nacional por Amostra } \\
\text { de Domicílios) e 2013: } \\
\text { PNS (Pesquisa Nacional } \\
\text { de Saúde) }\end{array}$ & $\begin{array}{l}\text { Brasil, grandes } \\
\text { regiões, estados } \\
\text { e capitais }\end{array}$ & 2008 e 2013 \\
\hline $\begin{array}{l}\text { Prevenção e } \\
\text { manutenção } \\
\text { da capacidade } \\
\text { funcional }\end{array}$ & $\begin{array}{l}\text { Proporção de idosos } \\
\text { com limitação funcional } \\
\text { para realizar atividades } \\
\text { de vida diária (AVD) }\end{array}$ & $\begin{array}{l}\text { Proporção de idosos de } 60 \text { anos ou mais que relatam não } \\
\text { conseguir ou ter grande dificuldade para realizar pelo menos } \\
\text { uma das atividades a seguir: (1) comer sozinho(a) com um } \\
\text { prato colocado à sua frente, incluindo segurar um garfo, cortar } \\
\text { alimentos e beber em um copo; (2) tomar banho sozinho(a) } \\
\text { incluindo entrar e sair do chuveiro ou banheira; ( } 3 \text { ) ir ao banheiro } \\
\text { sozinho(a), incluindo sentar e levantar do vaso sanitário; (4) se } \\
\text { vestir sozinho(a), incluindo calçar meias e sapatos, fechar o zíper, e } \\
\text { fechar e abrir botões; (5) andar em casa sozinho(a) de um cômodo } \\
\text { a outro da casa, em um mesmo andar, como do quarto para a sala } \\
\text { e cozinha; (6) deitar ou levantar da cama sozinho(a) }\end{array}$ & $\begin{array}{l}\text { 2013: PNS (Pesquisa } \\
\text { Nacional de Saúde) }\end{array}$ & $\begin{array}{l}\text { Brasil, grandes } \\
\text { regiões, estados } \\
\text { e capitais }\end{array}$ & 2013 \\
\hline $\begin{array}{l}\text { Violência e } \\
\text { maus-tratos }\end{array}$ & $\begin{array}{l}\text { Internação de idosos } \\
\text { por maus-tratos como, } \\
\text { pelo menos, uma das } \\
\text { causas }\end{array}$ & $\begin{array}{l}\text { Número de internações hospitalares financiadas pelo Sistema } \\
\text { Único de Saúde (SUS) por maus-tratos como pelo menos, uma das } \\
\text { causas de internação (CID-10 Y06-07) na população idosa de } 60 \\
\text { anos ou mais. }\end{array}$ & $\begin{array}{l}\text { SIH/SUS (Sistema } \\
\text { de Informações } \\
\text { Hospitalares do Sistema } \\
\text { Único de Saúde) }\end{array}$ & $\begin{array}{l}\text { Brasil, grandes } \\
\text { regiões, estados } \\
\text { e municípios }\end{array}$ & 2000 a 2015 \\
\hline \multirow{3}{*}{ Estilo de vida } & $\begin{array}{l}\text { Proporção de idosos } \\
\text { fumantes }\end{array}$ & $\begin{array}{l}\text { Percentual de idosos de } 60 \text { anos ou mais que fumam algum } \\
\text { produto de tabaco, em determinado espaço geográfico, no ano } \\
\text { considerado }\end{array}$ & $\begin{array}{l}\text { 2008: PNAD (Pesquisa } \\
\text { Nacional por Amostra } \\
\text { de Domicílios) e 2013: } \\
\text { PNS (Pesquisa Nacional } \\
\text { de Saúde) }\end{array}$ & $\begin{array}{l}\text { Brasil, grandes } \\
\text { regiões, estados } \\
\text { e capitais }\end{array}$ & 2008 e 2013 \\
\hline & $\begin{array}{l}\text { Proporção de idosos } \\
\text { que se alimentam } \\
\text { adequadamente }\end{array}$ & $\begin{array}{l}\text { Proporção de idosos de } 60 \text { anos ou mais que consumem cinco ou } \\
\text { mais porções diárias de frutas, legumes e verduras }\end{array}$ & $\begin{array}{l}\text { 2013: PNS (Pesquisa } \\
\text { Nacional de Saúde) }\end{array}$ & $\begin{array}{l}\text { Brasil, grandes } \\
\text { regiões, estados } \\
\text { e capitais }\end{array}$ & 2013 \\
\hline & $\begin{array}{l}\text { Proporção de consumo } \\
\text { abusivo e frequente de } \\
\text { álcool em idosos }\end{array}$ & $\begin{array}{l}\text { Proporção de idosos de } 60 \text { anos ou mais que ingerem } \\
\text { semanalmente altas doses de álcool (oito ou mais doses para } \\
\text { mulheres e } 15 \text { ou mais doses para homens) }\end{array}$ & $\begin{array}{l}\text { 2013: PNS (Pesquisa } \\
\text { Nacional de Saúde) }\end{array}$ & $\begin{array}{l}\text { Brasil, grandes } \\
\text { regiões, estados } \\
\text { e capitais }\end{array}$ & 2013 \\
\hline
\end{tabular}


(conclusão)

\begin{tabular}{|c|c|c|c|c|c|}
\hline Área temática & Indicador & Definição & Fonte & $\begin{array}{l}\text { Abrangência } \\
\text { geográfica }\end{array}$ & $\begin{array}{l}\text { Período } \\
\text { disponível }\end{array}$ \\
\hline Estilo de vida & $\begin{array}{l}\text { Proporção de idosos } \\
\text { fisicamente inativos }\end{array}$ & $\begin{array}{l}\text { Proporção de idosos que pratica menos de } 75 \text { minutos de atividade } \\
\text { intensa ou menos de } 150 \text { minutos de atividade leve ou moderadas } \\
\text { semanais no lazer }\end{array}$ & $\begin{array}{l}\text { 2013: PNS (Pesquisa } \\
\text { Nacional de Saúde) }\end{array}$ & $\begin{array}{l}\text { Brasil, grandes } \\
\text { regiões, estados } \\
\text { e capitais }\end{array}$ & 2013 \\
\hline $\begin{array}{l}\text { Moradia } \\
\text { adequada }\end{array}$ & $\begin{array}{l}\text { Proporção de idosos } \\
\text { que vivem em } \\
\text { domicílios adequados }\end{array}$ & $\begin{array}{l}\text { A categoria 'adequada' inclui os domicílios particulares } \\
\text { permanentes com rede geral de abastecimento de água, rede } \\
\text { geral de esgoto ou pluvial ou fossa séptica, coleta de lixo direta } \\
\text { por serviços de limpeza ou indireta em caçambas de serviços de } \\
\text { limpeza e até dois moradores por dormitório }\end{array}$ & $\begin{array}{l}\text { Censos Demográficos } \\
2000 \text { e } 2010\end{array}$ & $\begin{array}{l}\text { Brasil, grandes } \\
\text { regiões, estados } \\
\text { e municípios }\end{array}$ & 2000 e 2010 \\
\hline $\begin{array}{l}\text { Participação } \\
\text { social }\end{array}$ & $\begin{array}{l}\text { Proporção de idosos } \\
\text { que participam de } \\
\text { atividades organizadas }\end{array}$ & $\begin{array}{l}\text { Proporção de idosos de } 60 \text { anos ou mais que participam de } \\
\text { atividades sociais organizadas, como clubes, grupos comunitários } \\
\text { ou religiosos, centros de convivência de idosos etc. }\end{array}$ & $\begin{array}{l}\text { PNS (Pesquisa Nacional } \\
\text { de Saúde) }\end{array}$ & $\begin{array}{l}\text { Brasil, grandes } \\
\text { regiões, estados } \\
\text { e capitais }\end{array}$ & 2013 \\
\hline $\begin{array}{l}\text { Assistência } \\
\text { social }\end{array}$ & $\begin{array}{l}\text { Cobertura do } \\
\text { Benefício de Prestação } \\
\text { Continuada (BPC) }\end{array}$ & $\begin{array}{l}\text { Número de pessoas idosas beneficiárias do BPC na população idosa } \\
\text { elegível para o benefício }\end{array}$ & $\begin{array}{l}\text { Ministério do } \\
\text { Desenvolvimento } \\
\text { Social (MDS) e PNADs } \\
\text { contínuas }\end{array}$ & $\begin{array}{l}\text { Brasil, grandes } \\
\text { regiões, estados } \\
\text { e capitais }\end{array}$ & 2000 a 2017 \\
\hline
\end{tabular}

Fonte: Os autores (2019). 


\section{Acesso aos serviços de saúde}

O indicador proposto para avaliar o acesso de idosos aos serviços públicos de saúde foi a 'Proporção de idosos cadastrados na Estratégia Saúde da Família'. A atenção básica vem sendo o meio principal de ampliação da oferta pública de serviços à população ${ }^{35}$. Em conformidade com as Políticas Nacionais de Atenção Básica (PNAB) até então em vigor (Portarias MS/GM 648/06 $6^{36}$ e 2488/1137), as políticas de atenção à saúde do idoso consideram a atenção básica como a principal porta de entrada e centro de comunicação da Rede de Atenção à Saúde. Essas políticas tinham na Saúde da Família sua estratégia prioritária para expansão e consolidação

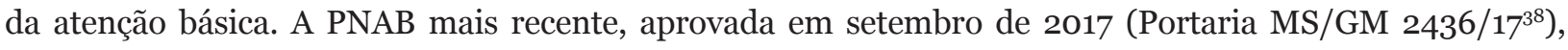
mantém pelo menos formalmente a ESF como forma preferencial de expansão da atenção básica. Contudo, é importante notar que, na prática, a posição da ESF está ameaçada pela possibilidade de arrecadação de recursos federais por outras formas de organização dos serviços ${ }^{1}$. Não obstante, o indicador ainda é o mais adequado porque consegue medir a expansão do acesso aos serviços de atenção básica nos últimos 11 anos.

\section{Prevenção e manutenção da capacidade funcional}

Para averiguar a manutenção da capacidade funcional da população idosa foi sugerido o indicador 'Proporção de idosos com limitação funcional para realizar Atividades de Vida Diária (AVD)'. Esse indicador compreende o desempenho sensitivo e motor na execução de tarefas e atividades específicas, consideradas subjacentes aos padrões fundamentais de organização diária de comportamento. Por este motivo, o indicador é sensível ao mais alto grau de limitação, o que, em geral, significa a impossibilidade de uma vida autônoma nos diversos aspectos relacionados pela CIF ${ }^{39,40}$. São considerados com limitação pessoas com 60 anos ou mais que referem não conseguir ou ter grande dificuldade para realizar pelo menos uma das atividades a seguir: (1) comer sozinho(a) com um prato colocado à sua frente, incluindo segurar um garfo, cortar alimentos e beber em um copo; (2) tomar banho sozinho(a) incluindo entrar e sair do chuveiro ou banheira; (3) ir ao banheiro sozinho(a) incluindo sentar e levantar do vaso sanitário; (4) vestir-se sozinho(a), incluindo calçar meias e sapatos, fechar o zíper, e fechar e abrir botões; (5) andar em casa sozinho(a) de um cômodo a outro da casa, em um mesmo andar, como do quarto para a sala e cozinha; (6) deitar ou levantar da cama sozinho(a).

Atualmente, no planejamento das ações de saúde pública, deve-se considerar o grau de incapacitação, dependência e necessidade de ajuda dos usuários do sistema ${ }^{39}$. Esse indicador cumpre a função de ser uma medida simples, válida e confiável, capaz de identificar e quantificar dependência no dia a dia e necessidade vital de ajuda. $P$ idosos com limitação para realizar AVD têm mais chance de gastos maiores com serviços de saúde², o que significa que seu investimento em prevenção deve ser redobrado.

\section{Violência e maus-tratos}

A violência contra a pessoa idosa é um tema importante tratado nas políticas públicas brasileiras. A ausência do tema na PNI é algumas vezes atribuída ao período de aprovação da lei ${ }^{41}$. De fato, na década de 1990, questões relativas à violação física, psicológica/emocional, sexual e financeira das pessoas idosas ainda não eram um tema pautado nas políticas de direitos humanos, e tinham tratamento incipiente na área da saúde. A partir da década de 2000, o tema ganha força, aparecendo, além de nas políticas supracitadas, na Política Nacional de Redução da Morbimortalidade por Acidentes Violentos (Portaria MS/GM 737/o142) e no Plano de Ação para o Enfrentamento da Violência Contra a Pessoa Idosa, de 200643.

A literatura nacional e internacional mensura a magnitude da violência contra a pessoa idosa como problema de saúde pública por meio do conceito de "causas externas", estabelecido pela OMS como referência aos tipos de violência resultantes de agressões e dos acidentes, traumas e lesões ${ }^{44}$. Apesar de importante, o conceito de "causas externas" é pouco sensível quando o objetivo é monitorar a violência, uma 
vez que engloba também lesões causadas por acidente de transporte, por quedas e por outras ocorrências provocadas por circunstâncias ambientais (como deslizamentos e enchentes). Por esse motivo, propomos como indicador para a avaliação das políticas voltadas para a pessoa idosa o número de internações de idosos por maus-tratos (homicídios, agressões, envenenamentos, suicídios, queimaduras) como, pelo menos, uma das causas da internação.

Números absolutos, tais como a contagem de incidência de um evento, não são, em geral, utilizados como indicadores de saúde porque não levam em conta o tamanho da população, o que impossibilita comparações temporais ou geográficas ${ }^{45}$. Contudo, eles podem ser utilizados quando as populações são pequenas ou quando se trata de eventos $\operatorname{raros}^{46}$, principalmente nos casos em que o caráter inaceitável do evento justifique tal tratamento.

\section{Estilo de vida}

Apesar de serem tratados de forma intermitente nas políticas voltadas para a pessoa idosa, fatores ligados ao estilo de vida são importantes fatores de risco para diversas doenças. O Plano de Ações Estratégicas para o Enfrentamento das Doenças Crônicas Não Transmissíveis (DCNT) ${ }^{47}$, de 2011 no Brasil, assinala que as DCNT têm entre suas causas fatores modificáveis ligados ao estilo de vida: "tabagismo, uso abusivo de álcool, inatividade física e alimentação inadequada" ${ }^{47}$. Considerando sua importância e o tratamento que recebem nas políticas públicas brasileiras, sugerimos quatro indicadores para monitorar a área temática do estilo de vida: 1) Proporção de idosos fumantes; 2) Proporção de idosos que se alimentam adequadamente; 3) Proporção de consumo abusivo e frequente de álcool em idosos; e 4) Proporção de idosos fisicamente inativos.

\section{Moradia adequada}

Uma moradia segura e apropriada é essencial para o bem-estar em todas as faixas etárias, sendo essencial para o envelhecimento ativo e saudável. Na idade avançada, o ambiente deve servir como facilitador, amortecedor e atenuador das dificuldades encontradas, propiciando as adaptações necessárias para a continuidade de uma vida independente e satisfatória ${ }^{48,49}$. O conceito de moradia adequada para pessoas idosas pode levar em conta diversos aspectos. Por um lado, podemos considerar como habitação adequada para essa população aquela que sofreu as modificações estruturais necessárias para ser adaptada a esta fase da vida (como, por exemplo, aparatos de segurança nos banheiros e altura das unidades de armários $)^{50}$. Por outro lado, do ponto de vista sanitário, a habitação tem sido abordada sob dois enfoques prioritários: 1) as condições da moradia que compreendem os materiais usados na sua construção e o acesso à eletricidade, aspectos decisivos para a oportunidade de adoecimento, como no paradigmático caso da moléstia de Chagas ${ }^{51}$, e 2) as condições de saneamento, as quais envolvem, principalmente, os serviços de abastecimento e de tratamento da água, o esgotamento sanitário e a coleta de lixo, considerados serviços básicos para o bom funcionamento dos domicílios ${ }^{52}$.

Levando em conta seu papel como determinante social de saúde, o indicador proposto -Proporção de idosos que vivem em domicílios adequados - utiliza uma definição que trata do padrão mínimo de aceitabilidade dos serviços de infraestrutura básica, além do espaço físico suficiente para seus moradores. Para isso, foram considerados adequados os domicílios que atendessem simultaneamente aos seguintes critérios: densidade de até dois moradores por dormitório; coleta de lixo direta ou indireta por serviço de limpeza; abastecimento de água por rede geral; e esgotamento sanitário por rede coletora ou fossa séptica. A densidade de moradores por dormitório é um dos indicadores que expressa a qualidade de vida na moradia e, em conjunto, com as características constitutivas e a disponibilidade de serviços básicos de infraestrutura são elementos que têm forte influência na saúde e no bem-estar da população. 


\section{Participação na comunidade}

A participação contínua nas questões sociais, econômicas, culturais, espirituais e civis é um importante componente do envelhecimento ativo ${ }^{49}$. Diversos estudos apontam que a diversidade de relações sociais e a elevada participação social são fatores importantes para a manutenção da capacidade funcional entre idosos ${ }^{53}$ e, por isso, é tratada em diversas políticas voltadas para a pessoa idosa. O indicador proposto para avaliar esta área temática é a proporção de idosos que participam de atividades organizadas, que inclui participação em clubes, grupos comunitários ou religiosos, centros de convivência de idosos, entre outras atividades.

É necessário lembrar que este indicador não mede todos os aspectos da participação social. Atividades realizadas com a família ou diversos tipos de atividades políticas não entram no cálculo do indicador.

\section{Assistência social}

As políticas públicas brasileiras no período democrático pós-1988 têm uma preocupação constante com a assistência social aos idosos em situação de pobreza. Isso se deve, pelo menos em parte, ao reconhecimento de que o processo de envelhecimento populacional no Brasil ocorreu em um contexto de desigualdade distributiva e com políticas sociais excludentes, voltadas apenas para os trabalhadores dos setores dinâmicos da economia ${ }^{54}$. Com isso, parcelas significativas da população foram excluídas do acesso aos serviços de saúde e previdência ${ }^{55} \mathrm{e}$ a população idosa atual chega muito vulnerável, se vê obrigada a altos gastos com saúde, depende de transferências públicas não contributivas e não conta com adequado suporte social, tão necessário nessa fase da vida. Essa garantia de renda mínima para as pessoas idosas prevista nas políticas supracitadas reiteram um direito garantido no art. 203, inciso V, da Constituição Federal de 198899 , que foi consolidado em nosso ordenamento jurídico com o nome de Benefício de Prestação Continuada (BPC) e regulamentado pela Lei Orgânica da Assistência Social - Loas (Lei 8.742/93) ${ }^{16}$.

O BPC é um benefício não contributivo voltado para idosos e pessoas com deficiência em situação de miséria. No caso do benefício por idade, o público-alvo do BPC são idosos (acima de 65 anos) que tenham renda familiar mensal inferior a um quarto do salário mínimo. Importante notar que, para fins do BPC, a renda familiar per capta é aquela proveniente do beneficiário, cônjuge, pais, madrasta ou padrasto, irmãos solteiros, filhos e enteados solteiros e menores tutelados, desde que vivam na mesma residência. Não entram no cálculo rendimento de programas sociais, como o bolsa família. Além disso, não são elegíveis para o BPC aqueles idosos que já recebam algum benefício previdenciário (aposentadoria ou pensão).

O indicador mais adequado para acompanhar a eficiência e eficácia desse tipo de programa é a sua cobertura, ou seja, se cada pessoa com características elegíveis está sendo atendida pelo benefício. Contudo, infelizmente o Brasil não dispõe de dados necessários para realizar com precisão esse tipo de estimativa ${ }^{56}$. Por um lado, o censo tem informações sobre a fonte de renda, mas não utiliza o mesmo conceito de família e não contém informações precisas sobre as relações familiares. Além disso, perguntas que detalham a fonte de rendimentos pertencem à amostra, e não ao universo. Por outro lado, a Pnad pergunta no questionário de domicílios quantas pessoas recebem o benefício, mas não identifica no questionário de pessoas quem são elas, o que impossibilita fazer o cômputo de renda das famílias. Por esse motivo, qualquer indicador de cobertura do BPC é impreciso, não obstante sua importância para o acompanhamento do programa.

Considerando os indicadores apontados, faremos uma breve exposição da situação do Brasil por área temática das políticas voltadas para a saúde da pessoa idosa. O objetivo da próxima seção é identificar o quanto os indicadores podem nos ajudar no acompanhamento dessas políticas públicas. 


\section{Evolução das diretrizes políticas no Brasil por áreas temáticas}

Neste segmento procuraremos traçar um panorama da situação de saúde dos idosos no Brasil e suas grandes regiões, partindo dos indicadores selecionados para o acompanhamento das áreas temáticas nas políticas.

A Tabela 1 mostra os resultados para Brasil e Grandes Regiões dos indicadores selecionados para as áreas temáticas 'acesso aos serviços de saúde', 'estilo de vida', 'moradia adequada', 'violência', 'manutenção da capacidade funcional' e 'participação social'.

Tabela 1 - Indicadores de políticas de saúde por área temática, por ano e grandes regiões

\begin{tabular}{|c|c|c|c|c|c|c|c|c|c|c|c|c|}
\hline & \multicolumn{2}{|c|}{ Norte } & \multicolumn{2}{|c|}{ Nordeste } & \multicolumn{2}{|c|}{ Sudeste } & \multicolumn{2}{|c|}{ Sul } & \multicolumn{2}{|c|}{ Centro-Oeste } & \multicolumn{2}{|l|}{ Brasil } \\
\hline & 2008 & 2013 & 2008 & 2013 & 2008 & 2013 & 2008 & 2013 & 2008 & 2013 & 2008 & 2013 \\
\hline \multicolumn{13}{|l|}{ Estilo de vida } \\
\hline $\begin{array}{l}\text { Consumo adequado de frutas legumes e } \\
\text { verduras }\end{array}$ & - & 31,5 & - & 25,1 & - & 35,7 & - & 30,2 & - & 39,5 & - & 32,2 \\
\hline Consumo abusivo e frequente de álcool & - & 14,8 & - & 19,1 & - & 26,1 & - & 30,3 & - & 21,3 & - & 24,1 \\
\hline Idosos fisicamente inativos & - & 35,5 & - & 35,2 & - & 35,8 & - & 45,7 & - & 34,7 & - & 37,4 \\
\hline Idosos fumantes & 16,1 & 12,2 & 18,0 & 14,8 & 12,1 & 11,1 & 14,9 & 14,4 & 14,9 & 11,4 & 14,5 & 12,6 \\
\hline \multicolumn{13}{|l|}{ Participação social } \\
\hline $\begin{array}{l}\text { Participação em atividades sociais } \\
\text { organizadas }\end{array}$ & - & 25,5 & - & 22,1 & - & 25,3 & - & 30,2 & - & 22,2 & - & 25,0 \\
\hline \multicolumn{13}{|l|}{$\begin{array}{l}\text { Prevenção e manutenção da capacidade } \\
\text { funcional }\end{array}$} \\
\hline Idosos com limitação AVD & _- & 5,7 & _- & 8,3 & _- & 5,8 & _ & 7 & _- & 8,1 & _- & 6,8 \\
\hline \multicolumn{13}{|l|}{ Acesso a serviços de saúde } \\
\hline Idosos cadastrados ESF & 54,1 & 54,1 & 67,3 & 68,7 & 35,8 & 48,7 & 52,2 & 59,9 & 54,1 & 56,8 & 48,6 & 56,3 \\
\hline \multicolumn{13}{|l|}{ Moradia adequada } \\
\hline & 2000 & 2010 & 2000 & 2010 & 2000 & 2010 & 2000 & 2010 & 2000 & 2010 & 2000 & 2010 \\
\hline $\begin{array}{l}\text { Idosos que vivem em domicílios } \\
\text { adequados }\end{array}$ & 26,3 & 36,2 & 41,6 & 55,1 & 72,7 & 78,6 & 65,8 & 75,3 & 60,8 & 72,4 & 60,1 & 69,3 \\
\hline
\end{tabular}

Fonte: Os autores, adaptado a partir dos dados da Pnad 2008, da PNS 2013, e do Censo 2000 e 2010 (2018). 
No que tange ao acesso aos serviços de saúde, os dados da Pnad e da PNS mostram que, de maneira geral, o acesso aos serviços básicos de saúde melhorou no Brasil entre 2008 e 2013, passando de 48,6\% dos idosos cobertos para 56,3\% neste período. A adesão à ESF foi maior no Nordeste e no Sul do país, mas a maior expansão do programa no período considerado aconteceu no Sudeste (de 35,8\% para 48,7\%). Vale destacar o caso do Norte, única região cuja cobertura da ESF para a população idosa permaneceu estável no período.

Quanto à prevenção e manutenção da capacidade funcional, vemos que 6,8\% dos idosos brasileiros têm alguma limitação funcional para realizar as AVD. As regiões com mais pessoas idosas nesta situação são o Nordeste $(8,3 \%)$ e o Centro-Oeste $(8,1 \%)$, e a que tem menos é o Norte $(5,7 \%)$.

Quanto ao estilo de vida das pessoas idosas, os dados da PNS nos permitem observar que, em 2013, apenas $32,2 \%$ dos idosos brasileiros se alimentavam adequadamente. A região com os piores resultados foi o Nordeste $(25,1 \%)$ e a que obteve os melhores foi o Centro-Oeste (39,5\%). Ainda de acordo com essa pesquisa, 24,1\% dos idosos brasileiros consomem álcool de forma abusiva e frequente, mas existe uma variação intensa entre as regiões, com algumas, como o Norte, tendo uma proporção muito menor do que a média nacional $(14,8 \%)$ e outras, como o Sul, muito superior (30,3\%).

Para a proporção de idosos fumantes temos dados que permitem a comparação entre dois pontos no tempo. É possível observar que, entre 2008 e 2013, o percentual caiu no Brasil cerca de 1,85\%. Apesar de todas as regiões terem registrado queda, em algumas, como o Norte ( $3,85 \%$ de queda), Centro-Oeste $(3,5 \%)$ e Nordeste $(3,1 \%)$, essa diminuição foi muito maior que em outras regiões, como o Sudeste $(0,99 \%)$ e o $\mathrm{Sul}(0,47 \%)$.

Quanto à inatividade física entre pessoas idosas, em razão da mudança da pergunta, entre a Pnad 2008 e a PNS 2013 não é possível fazer uma série histórica. Todas as regiões têm, em média, 30\% de pessoas idosas inativas fisicamente, sendo o percentual ligeiramente maior na região Sul (45,7\%). Quanto à participação social, $25 \%$ das pessoas idosas frequentam atividades sociais organizadas de forma frequente. Esse número é maior no Sul (30,2\%) e menor no Nordeste (22,1\%).

A moradia adequada - com esgotamento sanitário, coleta de lixo e água encanada - é um dos fatores ambientais mais importantes para a saúde da população. O Brasil tem avançado neste aspecto, passando de 60,1\%, em 2000, para 69,3\% em 2010. A região com maior proporção de idosos em moradia adequada é o Sudeste, cerca de 78,69\% em 2010, contudo é notável o avanço de outras regiões neste sentido. Dentre elas, podemos destacar o Centro-Oeste, que teve um aumento de 11,63\% em 10 anos, passando de 60,84\%, em 2000, para 72,47\% em 2010.

Sobre a área temática de combate à violência contra a pessoa idosa, verificou-se que todas as regiões registram poucos casos de internação por maus-tratos como pelo menos uma das causas, com notoriedade para o Norte e Centro-Oeste, que por diversos anos não registraram nenhum caso. As regiões Sul e Sudeste apresentaram maior número de internações por maus-tratos em relação às demais, no entanto isso pode ter ocorrido devido à grande subnotificação de casos, o que intensifica ainda mais a gravidade do problema de indicadores sobre esse tema.

Colaboradores, que estimaram o número potencial de pessoas idosas elegíveis ao BPC utilizando dados do Censo 2000 e compararam com o número de beneficiários nos registros administrativos, em 2005, para avaliar cobertura, concluíram que, em 2005, o benefício atingia 100\% de seu público-alvo, com uma leve sobrecobertura para homens (115\%) e subcobertura para mulheres (97\%).

\section{Discussão}

A partir dos resultados expostos na seção anterior discutiremos o uso e as limitações dos indicadores propostos para o planejamento e acompanhamento de ações em saúde pública. O panorama das políticas 
de saúde voltadas para a pessoa idosa vigentes no país mostrou que os instrumentos têm evoluído em consonância com o entendimento acadêmico e da comunidade internacional sobre o tema envelhecimento.

A identificação de áreas temáticas, por sua vez, mostra que existe um núcleo de preocupações consistente nas políticas públicas voltadas para este grupo etário no país, o que mostra a prioridade dessas questões para o setor estatal e, consequentemente, aumenta a necessidade de planejamento de ações de saúde para o seu enfrentamento e de indicadores para seu acompanhamento.

Foram propostos indicadores para cada uma das áreas temáticas considerando as fontes de dados de acesso público disponíveis no Brasil. É possível calcular indicadores de acompanhamento para todas as áreas temáticas, porém o seu uso apresenta algumas limitações importantes em termos de oportunidade, desagregabilidade e confiabilidade dependendo de sua fonte.

Os indicadores das dimensões de acesso aos serviços de saúde (proporção de idosos cadastrados na ESF), prevenção e manutenção da capacidade funcional (proporção de idosos com limitação funcional para realizar AVD), estilo de vida (proporção de idosos fumantes, proporção de idosos que se alimentam adequadamente, proporção de consumo abusivo e frequente de álcool entre idosos, e proporção de idosos fisicamente inativos) e participação social (proporção de idosos que participam de atividades organizadas) têm como fonte a Pnad 2008 e a PNS 2013, ou apenas esta última.

O longo intervalo dos dados e, nos casos em que a fonte é apenas a PNS, a impossibilidade de realizar uma série temporal consistente diminuem a sua utilidade para o acompanhamento de ações de saúde. Não obstante, é importante notar que essa característica não diminui a utilidade dos dados para o planejamento das intervenções de saúde pública. Contudo, o acompanhamento de políticas públicas depende de dados atualizados, de forma a permitir supervisão periódica a fim de identificar dificuldades que ocorram durante o processo de implementação para possibilitar correções ou adequações ${ }^{22}$.

Os indicadores que têm como fonte a Pnad e a PNS têm como problema adicional o fato de não serem desagregáveis para o nível municipal. Isso é um problema, principalmente em razão da expansão do papel dos municípios na formulação, acompanhamento e implementação de programas de saúde, que vem aumentando com os processos de descentralização e regionalização do SUS, iniciados com a Norma Operacional de Assistência à Saúde-SUS (NOAS-SUS 01/2001 e aprimorados pelo Pacto pela Saúde, de 2006 e, depois, o Contrato Organizativo de Ação Pública (Coap) de $2011^{20}$.

Para a área temática de prevenção e manutenção da capacidade funcional, a questão é ainda mais delicada, uma vez que as intervenções de saúde voltadas para esta área são frequentemente função da Atenção Primária em Saúde, que é de responsabilidade da gestão municipal. A falta de indicadores é um empecilho para a identificação de grupos vulneráveis e para o planejamento de intervenções. É importante ressaltar que, apesar do tema da manutenção da capacidade funcional estar presente em diversas políticas voltadas para a saúde da pessoa idosa, o Brasil só começou a produzir informações de base populacional sobre os diversos aspectos da funcionalidade com a PNS, em 2013, acrescentando ao problema da desagregabilidade a falta de uma série histórica e a distância de tempo entre a produção dos dados.

Por outro lado, o indicador da área temática de moradia adequada (proporção de idosos que vivem em domicílios adequados), que tem como fonte o Censo, tem alta desagregabilidade regional, mas tem uma periodicidade muito longa. Sua realização a cada dez anos impossibilita seu uso nos anos intercensitários.

Embora estudos mostrem a melhora da qualidade da informação, principalmente no que tange à mortalidade e às internações ${ }^{57}$, permanece como questão bastante relevante a confiabilidade dos dados. Elas são exemplificadas por problemas nos indicadores para as áreas temáticas de violência e maus-tratos (taxa de internação de idosos por maus-tratos como pelo menos uma das causas) e assistência social (cobertura do BPC).

Os dados sobre violência apresentados nos resultados deste artigo, de fato, levam ao levantamento de algumas questões, considerando que outros estudos sobre violência contra a pessoa idosa, realizados a 
partir de outras bases de dados, principalmente registros em delegacias, encontram resultados discrepantes quanto à magnitude do problema da violência ${ }^{58}$.

A hipótese é que isso se deva a um número importante de hospitalizações por causas externas contra idosos, as quais não tiveram a tais causas classificadas, o que redunda em subestimação das ocorrências por subgrupos específicos ${ }^{41}$. Por outro lado, diversos estudos apontam que nem todos os episódios de violência que ocorrem com os idosos chegam ao conhecimento dos serviços de saúde, principalmente em razão de grande parte da violência contra esse grupo etário ser perpetrada pelos familiares no ambiente doméstico ${ }^{59-61}$. Por último, os profissionais de saúde frequentemente não investigam os casos de violência no atendimento aos idosos. Souza e colaboradores ${ }^{62}$, em pesquisa realizada no estado do Rio de Janeiro, encontraram como principais razões para este fato: por um lado, os profissionais de saúde não se sentem aptos a fazê-lo, e, por outro, não existem protocolos para o registro deste tipo de violência. Os autores chegam à conclusão, a partir desses dados, que a ocorrência de violência contra pessoas idosas é sub-registrada porque os serviços de saúde não estão preparados para acolher, escutar, tratar e encaminhar o idoso.

Quanto à assistência social, como já mencionado, as bases de dados não permitem o cálculo preciso de cobertura do principal programa voltado para a garantia de renda mínima da população idosa, o BPC. A despeito disso, alguns estudos utilizam diversas metodologias para estimar a cobertura do benefício ${ }^{56,63,64}$. Agostinho e colaboradores ${ }^{63}$, por exemplo, estimam o número potencial de pessoas idosas elegíveis ao BPC utilizando dados do Censo 2000 e comparam com o número de beneficiários em 2004 e 2005 para avaliar a cobertura. Os autores concluem que o benefício já tinha atingido cobertura total de seu público-alvo em 2005.

É importante notar, contudo, que esse estudo não leva em conta erros de focalização do programa. Ou seja, ele assume que todos os beneficiários atendem perfeitamente aos critérios de elegibilidade, hipótese já refutada em outros estudos realizados com base na Pnad ${ }^{56,64}$. Ao considerar esse problema, o Tribunal de Contas da União (TCU) publicou relatório no qual estima que a cobertura real da população-alvo do BPC composta por pessoas idosas (aquelas em situação de miséria, que têm renda per capta familiar de até $1 / 4$ do salário mínimo) é de apenas 30\%. Apesar disso, o Tribunal considerou a focalização do programa boa, uma vez que a maior parte daqueles que recebem o benefício indevidamente estão em situação de pobreza (renda média per capta familiar de até $1 / 2$ salário mínimo) ${ }^{65}$.

Por último, é importante notar que os indicadores aqui apresentados contemplam apenas um aspecto do acompanhamento de políticas públicas. Uma avaliação mais abrangente depende de que outras dimensões sejam também levadas em consideração, tais como os recursos disponíveis para a implementação e se estes estão sendo utilizados. Uma metodologia desenvolvida para este tipo de análise para políticas de saúde da pessoa idosa está disponível no Sistema de Indicadores de Saúde e Acompanhamento de Políticas do Idoso (Sisap-Idoso), sistema desenvolvido pelo Laboratório de Informação em Saúde do Instituto de Comunicação e Informação Científica e Tecnologia em Saúde da Fundação Oswaldo Cruz (LIS/Icict/Fiocruz) em parceria com a Coordenação de Saúde da Pessoa Idosa do Ministério da Saúde (Cosapi/MS).

O Sisap-Idoso compreende um sistema de consulta de indicadores pela internet, de âmbito federal, estadual e municipal, sobre a saúde do idoso (https://sisapidoso.icict.fiocruz.br/20 ${ }^{20}$. A finalidade é oferecer uma ferramenta para a gestão do SUS que permita conhecer a situação de saúde da população idosa e, ao mesmo tempo, estabelecer processos contínuos de acompanhamento. A proposta do sistema é fornecer aos gestores e à sociedade como um todo dados úteis à formulação de políticas e ações de prevenção, além de contribuir para a melhoria da qualidade da assistência à saúde e da informação gerada nos níveis básicos de atenção do SUS. 


\section{Considerações finais}

Em um contexto de envelhecimento mundial, o Brasil se apresenta como pioneiro na promulgação de leis que visam à proteção social da pessoa idosa e na presença em acordos internacionais na área. Considerando o histórico das políticas públicas, foi possível observar não só o incremento do volume de áreas temáticas consideradas relevantes para a saúde da pessoa idosa, mas os avanços dentro de cada área temática.

No entanto, uma das limitações mais importantes para o monitoramento de planos, leis e políticas públicas de saúde é a deficiência na análise de informação relevante sobre aspectos fundamentais de sua qualidade de vida, especialmente pela carência de informação e indicadores adequados. Dados de qualidade precária não permitem alcançar os objetivos de sua coleta, provocam perda de recursos financeiros, interpretações errôneas da realidade e limitam o aprimoramento de políticas e estratégias de intervenção ${ }^{57}$.

No trabalho aqui apresentado foi realizada uma análise preliminar dos principais indicadores para acompanhamento de políticas públicas voltadas para pessoas idosas. Estudos mais aprofundados devem ser realizados levando em consideração gênero, faixa etária, capacidade funcional e comorbidades, entre outras variáveis que possam afetar a saúde dessa população.

O uso de dados secundários de diferentes fontes de informações para análise de políticas públicas apresenta algumas limitações uma vez que elas, em sua maioria, não foram criadas para esse fim. A primeira limitação refere-se à oportunidade dos dados, uma vez que algumas fontes importantes possuem longo intervalo entre suas atualizações. Um exemplo que se destaca é o dos censos demográfico, realizados a cada dez anos, o que torna seus dados pouco sensíveis à realidade nos anos intercensitários.

Outra limitação diz respeito à desagregabilidade dos dados. Algumas fontes não permitem a desagregação na esfera municipal, oquelimita a análise, especialmente, no âmbitolocal. Issoéum problema, principalmente em razão da expansão do papel dos municípios na formulação, acompanhamento e implementação de programas de saúde, que vêm aumentando com os processos de descentralização e regionalização do SUS, iniciados com a Norma Operacional de Assistência à Saúde-SUS (NOAS-SUS 01/2001) e aprimorados pelo Pacto pela Saúde, de 2006 e depois pelo Contrato Organizativo de Ação Pública (Coap) de 2011².

Por fim, destaca-se um frequente problema de confiabilidade dos dados: a subnotificação ou falta de preenchimento. Neste artigo é possível observar este problema especialmente no que diz respeito ao indicador Taxa de internação por maus-tratos. Pesquisas científicas apontam a subnotificação deste evento nos serviços de saúde, e atribuem esse fato a questões culturais, principalmente quando ocorrem no cenário familiar, contexto em que se verificam os maiores conflitos intergeracionais ${ }^{66}$.

De forma similar, um estudo que compara a produção e o acesso a indicadores para monitoramento de políticas de saúde e bem-estar da população idosa no Brasil e nos Estados Unidos, Rebouças e Pereira67 descreveram que, apesar de o Brasil produzir dados para o cálculo de cerca de 90\% dos indicadores utilizados pelo governo norte-americano, a pouca sistematização dos dados e a série histórica por vezes inconsistente dificultam sua utilização na rotina de planejamento, gestão e avaliação.

As dificuldades para a utilização de indicadores no monitoramento e na avaliação de políticas de saúde da pessoa idosa no Brasil são, portanto, muitas e variadas. Algumas delas estão sendo enfrentadas pela Política Nacional de Informação e Informática em Saúde - PNIIS (Portaria MS/GM 589/15) ${ }^{68}$. Esse instrumento aponta entre seus principais desafios a falta de padronização dos procedimentos para obtenção e tratamento dos dados em saúde e o elevado número de sistemas de informação em saúde e sua heterogeneidade. Contudo, a implementação da PNIIS depende de sua legitimação política ${ }^{69}$, o que pode ser comprometido pela diminuição dos recursos disponíveis no Novo Regime Fiscal Brasileiro implantado a partir de 2017. 


\section{Referências}

1. Vasconcelos AM, Gomes, MM. Transição demográfica: a experiência brasileira. Epidemiol Serv Saúde. 2012;21(4):539-48. doi: http://dx.doi.org/10.5123/S1679-49742012000400003

2. Lima-Costa MF, Peixoto SV, Giatti L. Tendências da mortalidade entre idosos brasileiros (1980-2000). Epidemiol Serv Saúde. 2004;13(4):217-28. doi: http://dx.doi.org/10.5123/S1679-49742004000400004

3. Mendes EM. As redes de atenção à saúde. Ci Saúde Coletiva. 2010;15(5):2297-2305. doi: http://dx.doi. org/10.1590/S1413-81232010000500005

4. Wong LL, Carvalho JA. O rápido processo de envelhecimento populacional do Brasil: sérios desafios para as políticas públicas. R Bras Est Pop 2006;23(1):5-26. doi: http://dx.doi.org/10.1590/S0102$\underline{30982006000100002}$

5. Miller T, Castanheira HC. The fiscal impact of population aging in Brazil: 2005-2050. R Bras Est Pop. 2013;30(supl.):S5-S23. doi: http://dx.doi.org/10.1590/S0102-30982013000400002

6. Banco Mundial. Relatório Envelhecendo em um Brasil mais velho: implicações do envelhecimento populacional para o crescimento econômico, a redução a pobreza, as finanças públicas e a prestação de serviços. Washington 2011. $64 \mathrm{p}$.

7. Franco R, Pardo MS, coordinadores. Institucionalidad Social en América Latina. Santiago de Chile: Cepal; Nações Unidas, UNFPA; 2010.

8. Huenchuan S, editor. Envejecimiento, derechos humanos y políticas públicas. Santiago de Chile: Cepal, Nações Unidas, Celade; 2009.

9. Brasil. Constituição da República Federativa do Brasil. Promulgada em 5 de outubro de 1988. Disponível em http://www.planalto.gov.br/ccivil 03/Constituicao/Constituicao.htm

10. Brasil. Lei $N^{\circ} 8.842$, de 04 de janeiro de 1994. Dispõe sobre a política nacional do idoso, cria o Conselho Nacional do Idoso e dá outras providências. Disponível em http://www.planalto.gov.br/ccivil 03/LEIS/ L8842.htm

11. Brasil. Ministério da Saúde. Portaria MS/GM N².528, de 19 de outubro de 2006. Aprova a Política Nacional de Saúde da Pessoa Idosa. Disponível em http://bvsms.saude.gov.br/bvs/saudelegis/gm/2006/ prt2528 $19 \quad 10 \quad 2006 . h t m l$

12. Brasil. Lei $N^{\circ} 10.741$, de $1^{\circ}$ de outubro de 2003. Dispõe sobre o Estatuto do Idoso e dá outras providências. Disponível em http://www.planalto.gov.br/ccivil_03/Leis/2003/L10.741.htm

13. Organização das Nações Unidas (ONU). Plano de ação internacional contra o envelhecimento, 2002. Brasília: Secretaria Especial dos Direitos Humanos, 2003.

14. Brasil. Ministério da Saúde. Portaria MS/GM N 399, de 22 de fevereiro de 2006. Divulga o Pacto pela Saúde 2006 - Consolidação do SUS e aprova as Diretrizes Operacionais do Referido Pacto. Disponível em http://bvsms.saude.gov.br/bvs/saudelegis/gm/2006/prt0399 $22 \quad 02$ 2006.html

15. Brasil. Decreto No 7.508, de 28 de junho de 2011. Regulamenta a Lei no 8.080, de 19 de setembro de 1990, para dispor sobre a organização do Sistema Único de Saúde - SUS, o planejamento da saúde, a assistência à saúde e a articulação interfederativa, e dá outras providências. Disponível em http://www. planalto.gov.br/ccivil 03/ ato2011-2014/2011/decreto/d7508.htm

16. Brasil. Lei № 8.741, de 07 de dezembro de 1993. Dispõe sobre a organização da Assistência Social e dá outras providências. Disponível em http://www.planalto.gov.br/ccivil 03/LEIS/L8742compilado.htm

17. Fleury S. A seguridade social inconclusa. In: Rocha $D$, Bernardo $M$, organizadores. A era FHC e o governo Lula: transição? Brasília: Inesc; 2004. p. 107-20

18. Monnerat GL, Souza RG. Da seguridade social à intersetorialidade: reflexões sobre a integração das políticas sociais no Brasil. R Katálysis. 2011;14(1):41-9. doi: http://dx.doi.org/10.1590/S141449802011000100005

19. Camarano AA. Introdução. In: Alcântara AO, Camarano AA, Giacomin KC, organizadores. Política Nacional do Idoso: velhas e novas questões. Rio de Janeiro: Ipea; 2016. p. 15-47.

20. Romero DE, Castanheira D, Marques AP, Muzi J, Sabaddini L, Silva RS. Metodologia integrada de acompanhamento de políticas públicas e situação de saúde: o Sisap-Idoso. Ci Saúde Coletiva. 2018;23(8):2641-50. doi: https://doi.org/10.1590/1413-81232018238.10302016 
21. Brasil. Ministério da Saúde. Portaria MS/GM No 2390, de 12 de dezembro de 1996. Fica instituída a Rede Integrada de Informações para a Saúde (RIPSA), com objetivos de estabelecer bases de dados consistentes, atualizadas, abrangentes, transparentes e de fácil acesso. Disponível em http://bvsms. saude.gov.br/bvs/saudelegis/gm/1996/PRT2390 11 12 1996.html

22. Jannuzzi PM. Indicadores para diagnóstico, monitoramento e avaliação de programas sociais no Brasil. $\mathrm{R}$ Serv Públ. 2005;56(2):137-60. doi: https://doi.org/10.21874/rsp.v56i2.222

23. Brasil. Decreto $N^{\circ}$ 1944, de 03 de julho de 1996. Regulamenta a Lei $n^{\circ} 8.842$, de 4 de janeiro de 1994 , que dispõe sobre a Política Nacional do Idoso, e dá outras providências. Disponível em: http://www. planalto.gov.br/ccivil 03/decreto/d1948.htm

24. Rauth J, Py L. A história por trás da lei: o histórico, as articulações de movimentos sociais e científicos, e as lideranças políticas envolvidas no processo de constituição da Política Nacional do Idoso. In: Alcântara AO; Camarano AA; Giacomin KC, organizadores. Política Nacional do Idoso: velhas e novas questões. Rio de Janeiro: Ipea; 2016. p. 51-62.

25. Brasil. Decreto N 3.321, de 30 de dezembro de 1999. Promulga o Protocolo Adicional à Convenção Americana sobre Direitos Humanos em Matéria de Direitos Econômicos, Sociais e Culturais "Protocolo de São Salvador", concluído em 17 de novembro de 1988, em São Salvador, El Salvador. Disponível em http://www.planalto.gov.br/ccivil 03/decreto/D3321.htm

26. World Health Organization. International Classification of functioning, disability and health: ICF. Geneva; 2001.

27. Ramos LR. Fatores determinantes do envelhecimento saudável em idosos residentes em centro urbano: Projeto Epidoso. Cad. Saúde Pública. 2003;19(3):793-8. doi: http://dx.doi.org/10.1590/S0102$\underline{311 \times 2003000300011}$

28. Alves LC, Leite IC, Machado CJ. Conceituando e mensurando a incapacidade funcional da população idosa: uma revisão de literatura. Ci Saúde Coletiva. 2008;13(4):1199-207. doi: http://dx.doi. org/10.1590/S1413-81232008000400016

29. Brasil. Ministério da Saúde. Portaria MS/GM N 1.395, de 13 de dezembro de 1999. Aprova a política nacional de saúde do idoso, cuja integra consta do anexo desta portaria e dela e parte integrante. (ementa elaborada pela CDI/MS). Disponível em https://goo.gl/o2sqdf

30. Brasil. Ministério da Saúde. Portaria MS/GM N 702, de 16 de abril de 2002. Cria mecanismos para a organização e implantação de redes estaduais de assistência à saúde do idoso. Disponível em https:// goo.gl/mghh6t

31. Brasil. Ministério da Saúde. Portaria MS/GM No 373, de 27 de fevereiro de 2002. Institui a Norma Operacional da Assistência à Saúde 01/2002 - NOAS-SUS 01/02. Disponível em http://bvsms.saude.gov. br/bvs/saudelegis/gm/2002/prt0373 2702 2002.html

32. Camarano AA, Mello JL. Cuidados de longa duração para idosos no Brasil: o arcabouço legal e as ações governamentais. In: Camarano AA, organizador. Cuidados de longa duração para a população idosa: um novo risco social a ser assumido? Rio de Janeiro: Ipea; 2010. p. 67-92

33. Geib LT. Determinantes sociais da saúde do idoso. Ci Saúde Coletiva. 2012;17(1):123-33. doi: http:// dx.doi.org/10.1590/S1413-81232012000100015

34. Nobrega IRAP, Leal MCC, Marques APO, Vieira JCM. Fatores associados à depressão em idosos institucionalizados: revisão integrativa. Saúde debate. 2015;39(105):536-50. doi: http://dx.doi. org/10.1590/0103-110420151050002020

35. Morosini MV, Fonseca AF. Reviewing the Brazilian National Primary Healthcare Policy at such a time?. Cad. Saúde Pública. 2017;33(1): doi: http://dx.doi.org/10.1590/0102-311x00206316

36. Brasil. Ministério da Saúde. Portaria MS/GM No 648, de 28 de março de 2006. Aprova a Política Nacional de Atenção Básica, estabelecendo a revisão de diretrizes e normas para a organização da atenção básica para o Programa Saúde da Família (PSF) e o Programa Agentes Comunitários de Saúde (PACS). Disponível em http://bvsms.saude.gov.br/bvs/saudelegis/gm/2006/prt0648 2803 2006.html 
37. Brasil. Ministério da Saúde. Portaria MS/GM № 2.488, de 24 de outubro de 2011. Aprova a Política Nacional de Atenção Básica, estabelecendo a revisão de diretrizes e normas para a organização da atenção básica, para a Estratégia Saúde da Família (ESF) e o Programa de Agentes Comunitários de Saúde (PACS). Disponível em http://bvsms.saude.gov.br/bvs/saudelegis/gm/2011/prt2488 $21 \quad 10$ 2011.html

38. Brasil. Ministério da Saúde. Portaria MS/GM No 2.436, de 21 de setembro de 2017. Aprova a Política Nacional de Atenção Básica, estabelecendo a revisão de diretrizes para a organização da Atenção Básica, no âmbito do Sistema Único de Saúde (SUS). Disponível em http://bvsms.saude.gov.br/bvs/saudelegis/ gm/2017/prt2436 2209 2017.html

39. Ramos LR, Andreone S, Coelho-Filho JM, Lima-Costa MF, Matos DL, Rebouças M, et al. Perguntas mínimas para rastrear dependência em atividades da vida diária em idosos. R Saúde Pública. 2013;47(3):506-13. doi: http://dx.doi.org/10.1590/S0034-8910.2013047004325

40. Rebouças M, Coelho JM, Veras RP, Lima-Costa MF, Ramos LR. Validade das perguntas sobre atividades da vida diária para rastrear dependência em idosos. R Saúde Pública. 2017;51:84. doi: https://doi. org/10.11606/S1518-8787.2017051006959

41. Souza ER, Minayo MC. Inserção do tema violência contra a pessoa idosa nas políticas públicas de atenção à saúde no Brasil. Ci. Saúde Coletiva. 2010;15(6):2659-68. doi: http://dx.doi.org/10.1590/ $\underline{\mathrm{S} 1413-81232010000600002}$

42. Brasil. Ministério da Saúde. Portaria MS/GM № 737, de 16 de maio de 2001. Aprova, na forma do anexo desta portaria, a Política Nacional de Redução da Morbimortalidade por Acidentes e Violências. Disponível em http://bvsms.saude.gov.br/bvs/saudelegis/gm/2001/prt0737 1605 2001.html

43. Brasil. Presidência da República. Subsecretaria de Direitos Humanos. Plano de Ação para o Enfrentamento da Violência Contra a Pessoa Idosa. Brasília: Subsecretaria de Direitos Humanos; 2005.

44. Souza DJ, White HJ, Soares LM, Nicolasi GT, Cintra FA, D'Elboux MJ. Maus-tratos contra idosos: atualização dos estudos brasileiros. R Bras Geriatr Gerontol. 2010;13(2):321-328. doi: http://dx.doi. org/10.1590/S1809-98232010000200016

45. Soares DA, Andrade SM, Campos JJ. Epidemiologia e indicadores de saúde. In: Andrade SM, Soares, DA, Cordoni Junior L, organizadores. Bases da saúde coletiva. Londrina: Ed. UEL; 2001. p. 183-210.

46. Merchan-Hamann E, Tauil PL, Costa MP. Terminologia das medidas e indicadores em epidemiologia: subsídios para uma possível padronização da nomenclatura. Inf. Epidemiol. Sus. 2000;9(4):276-84.

47. Brasil. Ministério da Saúde. Secretaria de Vigilância em Saúde. Departamento de Análise de Situação de Saúde. Plano de ações estratégicas para o enfrentamento das doenças crônicas não transmissíveis (DCNT) no Brasil 2011-2022. Brasília: Ministério da Saúde; 2011.

48. Tomasini SL. Envelhecimento e planejamento do ambiente construído: em busca de um enfoque interdisciplinar. R Bras Ci Envelh Hum. 2005;2(1):76-88. doi: https://doi.org/10.5335/rbceh.2012.22

49. World Health Organization. Envelhecimento ativo: uma política de saúde. Suzana Gontijo, tradutora. Brasília: Organização Pan-Americana da Saúde; 2005.

50. Wahl HW, Weisman GD. Environmental gerontology at the beginning of the new millennium: reflections on its historical, empirical, and theoretical development. Gerontologist. 2003;43(5):616-27.

51. Magalhaes KA, Cotta RMM, Martins TCP, Gomes AP, Siqueira-Batista R. A habitação como determinante social da saúde: percepções e condições de vida de famílias cadastradas no programa Bolsa Família. Saude Soc. 2013;22(1):57-72. doi: https://doi.org/10.1590/s0104-12902013000100007

52. Instituto Brasileiro de Geografia e Estatística. Síntese de Indicadores Sociais. Uma Análise das Condições de Vida da População Brasileira 2007. Rio de Janeiro; 2007. (Estudos \& Pesquisas. Informação Demográfica e Socioeconômica; n²1).

53. Avlund $\mathrm{K}$, Lund R, Holstein BE, Due P. Social relations as determinant of onset of disability in aging. Arch Gerontol Geriatr. 2004;38(1):85-99.

54. Medeiros MA. Trajetória do welfare state no Brasil: papel redistributivo das políticas sociais dos anos 1930 aos anos 1990. Texto Discus 2001:(852).

55. Gerschman S, Vianna ML. A Miragem da pós-modernidade: democracia e políticas sociais no contexto da globalização. Rio de Janeiro: Editora Fiocruz; 2002. 
56. Medeiros M. A distribuição das transferências, público-alvo e cobertura do Benefício de Prestação Continuada. R Textos Contextos. 2009;8(2):358-76.

57. Romero $\mathrm{D}$, Cunha $\mathrm{CB}$. Avaliação da qualidade das variáveis socioeconômicas e demográficas dos óbitos de crianças menores de um ano registrados no Sistema de Informações sobre Mortalidade do Brasil (1996/2001). Cad Saúde Pública 2006;22(3): 673-81. doi: http://dx.doi.org/10.1590/S0102$\underline{311 \times 2006000300022}$

58. Pasinato MT, Camarano AA, Machado Laura. Idosos vítimas de maus-tratos domésticos: estudo exploratório das informações levantadas nos serviços de denúncia. Texto Discus. 2010:1200.

59. Minayo MC. A difícil e lenta entrada da violência na agenda do setor saúde. Cad Saúde Pública 2004;20(3):646-47. doi: http://dx.doi.org/10.1590/S0102-311X2004000300001

60. Souza ER. O estado de direito e a violência contra o idoso. Relatório final de pesquisa. Rio de Janeiro: Claves; 2006.

61. Souza AC. A violência contra os idosos. In: Njaine K, Assis SG, Constantino P, organizadores. Impactos da violência na saúde. Rio de Janeiro: Editora Fiocruz; 2009. p. 183-95.

62. Souza ER, Ribeiro AP, Atie S, Souza AC, Marques CC. Rede de proteção aos idosos do Rio de Janeiro: um direito a ser conquistado. Ci Saúde Coletiva 2008;13(4):1153-63. doi: http://dx.doi.org/10.1590/S1413$\underline{81232008000400011}$

63. Agostinho C, Sawyer D.; Carvalho J, Freitas A, Queiroz B, Máximo G. Estimativa do público-alvo do BPC e sua cobertura. In: Vaitsman J, Paes-Souza R, organizadores. Políticas e Programas do MDS: resultados. Brasília: MDS, 2007. v. 2, p. 257-81.

64. Soares $\mathrm{F}$ et al. Programas de transferência de renda no Brasil: impactos sobre a desigualdade. Texto Discus. 2006:(1228).

65. Tribunal de Contas da União (BR). Relatório de auditoria operacional: benefício de prestação continuada da assistência social. Relator Ministro Augusto Nardes; Brasília; 2009. 146 p.

66. Oliveira AAV, Trigueiro DRSG, Fernandes MGM, Silva AO. Maus-tratos a idosos: revisão integrativa da literatura. Rev Bras Enferm. 2013;66(1):128-33. doi: http://dx.doi.org/10.1590/S0034$\underline{71672013000100020}$

67. Rebouças M, Perreira MG. Indicadores de saúde para idosos: comparação entre o Brasil e os Estados Unidos. Rev Panam Salud Publica 2008;23(4):237-46.

68. Brasil. Ministério da Saúde. Portaria MS/GM No 589, de 20 de maio de 2015. Institui a Política Nacional de Informação e Informática em Saúde (PNIIS). Disponível em http://bvsms.saude.gov.br/bvs/ saudelegis/gm/2015/prt0589_20 05_2015.html

69. Cavalcante RB, Kerr-Pinheiro MM, Guimarães EAA, Miranda RM. Panorama de definição e implementação da Política Nacional de Informação e Informática em Saúde. Cad Saúde Pública. 2015;31(5):960-70. doi: http://dx.doi.org/10.1590/0102-311X00095014 